\title{
NRR Changes: Editorial
}

\author{
Emmanuel John M. Carranza ${ }^{1,2}$
}

It is now more than a year since I assumed the Editor-in-Chief (EiC) post of Natural Resources Research (NRR). This change for NRR coincides with changes in my work and location. In addition to changes in the editorial board that I have made since assuming the EiC post, there were other important changes that occurred for NRR in 2013.

First, since February 2013, Petra van Steenbergen (Springer, Dordrecht) has taken over from Chris Bendall (Springer, Heidelberg) the overall management of NRR. Second, since March 2013, Fran Hein (Alberta Energy Regulator, Canada; Chair, Energy Minerals Division Gas (Tight) Sands Committee) has taken over from Doug Peters (ARNEVUT Resources Inc.) the Deputy Editor post. On behalf of Springer and IAMG (International Association for Mathematical Geosciences), I thank Doug for the valuable services he has given to NRR over the years. Third, since March 2013, print copy of NRR has a new cover image; and, we plan to change NRR's print copy cover every 2 years.

Last year we were unable to publish an article from our co-sponsor the Energy Minerals Division (EMD) of the American Association of Petroleum Geologists (AAPG). Since 2007 and every 2 years thereafter, the EMD-AAPG publishes in NRR unconventional energy resource commodity summaries prepared by its committees. We missed to publish the article of the EMD-AAPG last year because its proofs were sent to the corresponding author for checking during the 16-day U.S. federal government shutdown in October 2013, and the corresponding author is from the U.S. Geological Survey. This article is now published in this issue.

\footnotetext{
${ }^{1}$ School of Earth and Environmental Sciences, James Cook University, Townsville QLD, Australia.

${ }^{2}$ To whom correspondence should be addressed; e-mail: john.carranza@jcu.edu.au
}

We will strive to be on time with publishing our cosponsor's articles in the future issues of NRR.

I was curious to see if there are differences in the contents of papers in 2013 compared to those in 2012, and so I created word clouds for the abstracts of papers in each year (Fig. 1). There are some notable similarities in terms of the general type of natural resources, namely energy resources, that were discussed in the 2012 and 2013 papers. A striking difference is that many 2012 papers discussed groundwater be on time with whereas many 2013 paper discussed water. This reflects that many 2013 papers discussed surface rather than subsurface waters, and environmental impact on surface waters. This focus on environmental impact on water resources, in many 2013 papers, is further reflected by the predominance of ' $\mathrm{Cd}$ ' and 'release' in the right panel in Figure 1, implying heavy metal contamination of water. Another striking difference is the predominance of 'model', 'data', 'simulation' and 'modelling' in many 2013 papers whereas, of these terms, only 'modelling' is prevalent in some 2012 papers. This reflects that many 2013 papers focused on quantitative analysis of certain natural resources whereas only a few of the 2012 papers had that focus. I hope that NRR continues to receive more papers dealing with quantitative approaches to natural resources exploration, assessment, extraction and utilisation.

An unpleasant change is the sharp decrease in the 'cites/doc (2 years)' of NRR for 2012 (Fig. 2). This index is the same as impact factor of ISI-indexed journals. Yet, it is good to see that the SJR index of NRR continues to increase. This index is a measure of the scientific influence of a journal article and it expresses how central to global scientific discussion a journal article is. However, the quality indices for 2012 represent papers published in 2011 and 2010. Therefore, I look forward to 2105 when I will see the influence of my taking up the EiC post of NRR. 


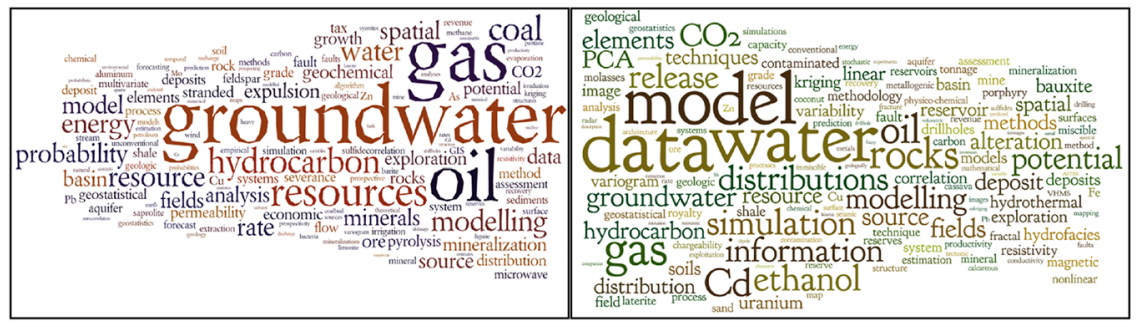

Figure 1. Word clouds created using Wordle (http://www.wordle.net/) for the abstracts of NRR papers in 2012 (left panel) and 2013 (right panel).

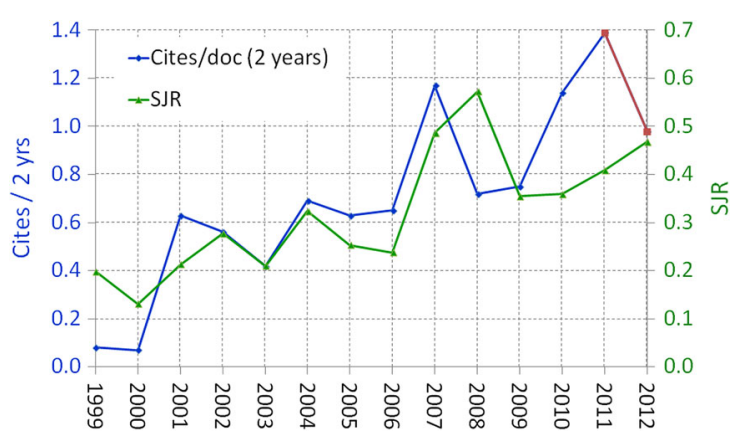

Figure 2. Annual impact factors of NRR. Source: SCImago Journal \& Country Rank (http://www.scimagojr.com/index.php).

\section{REVIEWERS LIST}

I acknowledge and thank the reviewers of our papers in the preceding year, some of who has reviewed more than one paper.

Agterberg, Frits (2)

Aldolzadeh, Ahmad

Alexander, Russel

Alvarado, Vladimir

Balsingame, Tom

Bardsley, Earl

Bertolini, L. C.

Buccianti, Antonella

Bünzli, Jean-Claude G.

Burnett, J. W.

Carranza, John

Coburn, Timothy

Craig, James

Cromarty, Duncan

Dahiya, Rita

de Marsily, Ghislain

Deutsch, Clayton

Doerre, Andrei
Domingo, Concepcion

Ebenhack, B. W.

Furlonge, $\mathrm{H}$.

Gauch, H. G., Jr.

Gheewala, Shabbir

Peters, Douglas

Pimentel, David (2)

Plötze, M.

Porwal, Alok

Prasad, R.

Pyrcz, Michael

Rajapakse, R. M. G.

Rajesh, H. M.

Ranjbar, H.

Rantitsch, Gerd

Reddy, A. G. S. (2)

Samal, Abani (2)

Schuenemeyer, Jack

Shields, Deborah

Singer, Donald

Smith, B. D.

Soeder, Daniel

Sophocleous, Marios (2)

Sy, Charlie

Thomas, Dean

Van Oss, Hendrik

Wang, Anjian

Wang, Qingfei (2)

West, Jason

Willis, Brian

Wilson, Chris

Wyns, R.

$\mathrm{Xu}$, Dayong

Yigit, O.

Yu, Shiwei

Zhu Guangyou

Zuo, Renguang (2) 